$\xi=-1$

\title{
Conductivity and structural studies of PVA based mixed-ion composite polymer electrolytes
}

\author{
Sandeep Srivastava ${ }^{1}$, Pradeep K. Varshney ${ }^{2}$ \\ ${ }^{I}$ Department of Physics, Faculty of Engineering \& Technology, Manav Rachna International Institute of Research and Studies, \\ Faridabad, Haryana, India \\ ${ }^{2}$ Department of Chemistry, Faculty of Engineering \& Technology, Manav Rachna International Institute of Research and Studies, \\ Faridabad, Haryana, India \\ *Corresponding author E-mail: sandeepsri1973@gmail.com
}

\begin{abstract}
The solid membranes having different ratios of poly-vinyl alcohol (PVA), sodium perchlorate $\left(\mathrm{NaClO}_{4}\right)$ and lithium perchlorate $(\mathrm{LiClO} 4)$ were prepared using solution casting technique. The mixed-ion composite polymer electrolytes were characterized by X-ray diffraction analysis (XRD), Fourier transform infrared spectroscopy (FTIR) and conductivity measurement investigations. The XRD study confirms the amorphous nature of the mixed-ion composite polymer electrolytes. FTIR analysis has been used to characterize the structure of polymer which confirms the polymer and salt complex formation. The temperature dependent nature of ionic conductivity of the mixed-ion composite polymer electrolytes was determined by using conductivity meter (EC-035WP ERMA Inc, made in Japan). The ionic conductivity of the electrolyte was found in the range of $10^{-3}-10^{-4} \mathrm{~S} / \mathrm{cm}$ at room temperature.
\end{abstract}

Keywords: FTIR; Ionic Conductivity; Mixed-Ion Composite Polymer Electrolyte; XRD.

\section{Introduction}

The application of solid polymer electrolytes in electrochemical storage devices, super capacitors, fuel cells and sensors are increasing day by day since last few decades [1-4]. Extensive studies and research have been committed towards improvement in conductivity of solid polymer electrolyte materials at ambient temperature for their potential application in electrochemical devices. Several modifications such as incorporation of various salts [5-11], plasticizers [12-14] and fillers [15-16] in solid polymer electrolytes have been explored to improve their performance in electrochemical device applications. The exploration of new materials has been done during the past few decades that can replace the conventional materials with improved characteristics. The mixed ion composite polymers are fulfilling the requirements of such materials in modern era. The mixed-ion composite polymers are produced by combination of two or more components and are heterogeneous on microscopic scale [9-10].

The present work aims at the introduction of an economical mixed-ion composite polymer material which can be used in electrochemical devices with good performance comparable with present electrolytes of mixed-ion nature. This paper gives an account of crystallization character, structural analysis and ionic conduction of the new mixed-ion composites of PVA with inorganic salts.

\section{Materials and method}

\subsection{Experimental}

Poly (vinyl alcohol) PVA (molecular weight $=1,25,000$ ) was purchased from $\mathrm{CDH}$, sodium perchlorate $\left(\mathrm{NaClO}_{4}\right)$ and lithium perchlorate $\left(\mathrm{LiClO}_{4}\right)$ were purchased from Sigma Aldrich. Weighing of polymers and salts was done on Toledo Metller electronic balance.

The stock solutions of sodium perchlorate $\left(\mathrm{NaClO}_{4}\right)$ and lithium perchlorate $\left(\mathrm{LiClO}_{4}\right)$ were prepared and later used to prepare different mixed ion composite polymer electrolytes. The salts were added to the polymer in various concentrations $(5 \%, 10 \%, 15 \%$, $20 \%, 25 \%$ and $30 \% \mathrm{w} / \mathrm{v}$ ) to make composites of different compositions.

The solutions of electrolytes were prepared by mixing of PVA (20\%) with $\mathrm{NaClO}_{4}$ and $\mathrm{LiClO}_{4}$ at different ratios in distilled water to get $\mathrm{PVA}+\mathrm{NaClO}_{4}, \mathrm{PVA}+\mathrm{LiClO}_{4}$ and $\mathrm{PVA}+\mathrm{NaClO}_{4}+\mathrm{LiClO}_{4}$ complex electrolytes. The solutions were then stirred continuously using stirrer for 8 hours on a hot plate at $60^{\circ} \mathrm{C}$ to obtain a homogeneous mixture. Finally, prepared solutions of mixed ion composites were placed in $80 \times 15 \mathrm{~mm}$ diameter Borosil petri dishes for further annealing at room temperature. The petri dishes were covered with aluminium foil to avoid any contamination from environment. Five different samples of polymer electrolytes were prepared and subjected to characterization.

\subsection{Characterization techniques}

Temperature dependent conductivity of the samples was measured by pen type conductivity meter (EC-035WP ERMA Inc, made in Japan) at varying temperatures. Mixed-ion composite polymer electrolyte samples of $1 \mathrm{~mm}$ thickness and $10 \mathrm{~mm} \times 10 \mathrm{~mm}$ dimension were placed between the electrodes of conductivity meter. The thicknesses of samples were measured by screw gauge. 
Fourier Transform Infrared Spectrum is a fingerprint which provides us ample information about the structure of compound. In order to elucidate the temperament and complexation between polymer and salt, FTIR spectra have been recorded on Bruker Tensor-37 spectrophotometer in the wavenumber range between $4000-500 \mathrm{~cm}^{-1}$.

The XRD pattern analysis of the synthesized samples was carried out on RIGAKU JAPAN ULTIMA-IV X-ray diffractometer to observe the nature of the developed films. The sample of $10 \mathrm{~mm}$ size was mounted on sample holder and placed in diffractometer. The samples were scanned in $2 \theta$ range of $10^{\circ}-80^{\circ}$ with X-rays using $\mathrm{Cu}$ target source for crystalline phase identification of these mixed ion polymeric composites.

\section{Results and discussion}

\subsection{FTIR spectroscopy}

In order to determine the possible nature of bonding between various functional groups in the samples, FTIR spectroscopy was used and the results are presented in figure- 1 . The complex formation in the polymer matrices was evidenced through FTIR studies. FTIR spectra of composite prepared by mixing PVA with sodium perchlorate, lithium perchlorate and both lithium and sodium perchlorate, is shown in Fig. 1(b to d) and compared with that of pure PVA (Fig. 1a).

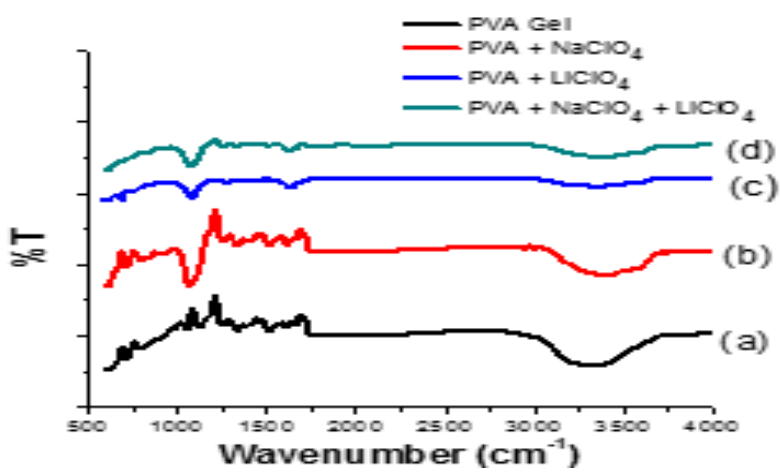

Fig. 1: FTIR Spectra of (A) PVA, (B) PVA/NaClO $\mathrm{PVA} / \mathrm{NaClO}_{4}+\mathrm{LiClO}_{4}$

Predominant absorption bands were observed at around 3365$3297 \mathrm{~cm}^{-1}$ in IR spectrum of pure PVA which were displaced to higher wavenumbers indicating specific interactions in the polymer matrices [17].

These bands can be attributed to stretching vibrations of $\mathrm{OH}-$ groups originated from residual water and those from the organic counterpart (PVA) [18]. Additionally, in the IR spectrum of pure PVA, absorption signal at about $2951 \mathrm{~cm}^{-1}$ was also observed which was resulting from $\mathrm{C}-\mathrm{H}$ asymmetric stretching vibrations of $\mathrm{CH}$ and $\mathrm{CH}_{2}$ groups. This band was shifted to $2954-2957 \mathrm{~cm}^{-1}$ in PVA based complexes.

The peaks appearing at $1257 \mathrm{~cm}^{-1}$ and $1128 \mathrm{~cm}^{-1}$ were assigned as originating from $\mathrm{C}-\mathrm{O}$ bond deformation $[19]$ and $\mathrm{C}-\mathrm{C}$ stretching vibrations respectively. However, the corresponding peaks are not clearly visible in the spectra of PVA based complexes due the appearance of a strong band at $1089-1070 \mathrm{~cm}^{-1}$. These intense peaks were due to the $\mathrm{ClO}_{4}{ }^{-}$asymmetric stretching vibrations [20]. The peaks appearing in the range of $802-808 \mathrm{~cm}^{-1}$ in IR spectra of PVA and its composite were assigned as arising from $\mathrm{C}-\mathrm{H}$ rocking mode [17-18]. The peaks at $616-621 \mathrm{~cm}^{-1}$ in PVA based complexes are assigned to $\mathrm{ClO}_{4}^{-}$asymmetric bending type of vibrations [20].

\subsection{X-ray analysis}

To scrutinize the nature of crystallinity of pure PVA film and PVA/salt composite polymer electrolyte films, X-ray diffraction patterns were obtained from X-ray diffractometer. X-ray diffraction patterns of polymer/salt composite systems of PVA, $\mathrm{PVA} / \mathrm{NaClO}_{4}, \mathrm{PVA} / \mathrm{LiClO}_{4}$ and $\mathrm{PVA} / \mathrm{NaClO}_{4}+\mathrm{LiClO}_{4}$ in different proportions are shown in Fig.-2. It is observed that the maximum intensity of diffraction spectrum for pure PVA film is at $2 \theta=$ $20^{\circ}$ which shows a typical semi-crystalline structure of PVA [21]. The nature of the peak and its intensity was also altered due to the addition of salts in various proportions [5-6], [22-25]. The reduction in peak intensity shows the amorphous nature of

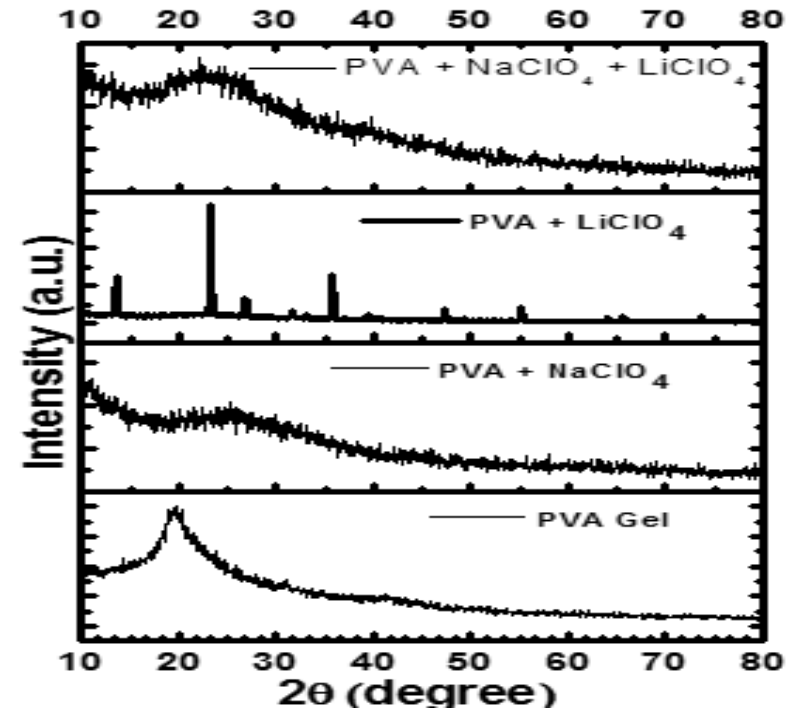

Fig. 2: X-Ray Diffraction of $\mathrm{PVA}, \mathrm{PVA} / \mathrm{NaClO}_{4}, \mathrm{PVA} / \mathrm{LiClO}_{4}$ and $\mathrm{PVA} / \mathrm{NaClO}_{4}+\mathrm{LiClO}_{4}$

composite polymer electrolyte. The mixed-ion composite polymer electrolytes have been prepared by the addition of sodium perchlorate and lithium perchlorate to different proportions of PVA. The observed XRD patterns of such mixed-ion composite polymer electrolytes confirm the amorphous nature of this composite system and this nature varies with different salts combinations, because the crystalline configuration of the polymer vanishes with mixing of different salts [26].

\subsection{Temperature dependence of conductivity}

The conductivity values of various samples are shown in Table-1. The conductivity followed the typical trend of polymer salt complexes [27]. An increase in conductivity of mixed-ion composite liquid polymer electrolyte was noticed on increasing the temperature which may be attributed to the complete dissociation of salt in liquid resulting in higher mobile ion concentration and flexibility of polymer electrolyte [28-29].

The variations of conductivity (ln $\sigma$ ) with reciprocal of temperature $\left(\mathrm{K}^{-1}\right)$ for various mixed-ion polymer composites are shown in Fig.-3.

The temperature dependent conductivity of mixed-ion composite polymer follows a linear pattern which indicates Arrhenius behavior. Hence the activation energy was calculated from the following relation:

$$
\sigma=\sigma_{\mathrm{o}} \exp \left(-\mathrm{E}_{\mathrm{A}} / \mathrm{kT}\right)
$$

where $\sigma_{0}$ is the pre-exponential factor, $\mathrm{E}_{\mathrm{A}}$ is the activation energy, $\mathrm{k}$ is Boltzmann constant, and $\mathrm{T}$ is absolute temperature. The calculated values of activation energy for mixed-ion composites range from 0.09 to $0.10 \mathrm{eV}$. These low values of activation energy suggest an amorphous nature of the mixed-ion composite polymer electrolyte. 
Table 1: Ionic Conductivity of PVA Based Mixed-Ion Electrolyte at Various Polymer Compositions with Salts $\mathrm{NaClO}_{4}, \mathrm{LiClO}_{4}$ and $\mathrm{NaClO}_{4}+$ $\mathrm{LiClO}_{4}$.

\begin{tabular}{cccc}
\hline \multicolumn{4}{c}{ Natural log of conductivity $(\ln \sigma)$} \\
\hline $\begin{array}{c}\text { PVA } \\
1000 / \mathrm{T}\left(\mathrm{K}^{-1}\right)\end{array}$ & $\begin{array}{c}\mathrm{PVA} \\
+\mathrm{NaClO}_{4}\end{array}$ & $\begin{array}{c}\mathrm{PVA} \\
\mathrm{LiClO}_{4}\end{array}$ & $+\mathrm{NaClO}_{4}+\mathrm{LiClO}_{4}$ \\
3.355704698 & -6.778482943 & -6.70890442 & -6.45667966 \\
3.300330033 & -6.852320572 & -6.75075153 & -6.489044944 \\
3.246753247 & -6.914779894 & -6.79442659 & -6.515713191 \\
3.194888179 & -6.974964029 & -6.86661334 & -6.578451532 \\
3.144654088 & -7.024289095 & -6.90975728 & -6.637728142 \\
3.095975232 & -7.055095867 & -6.94649611 & -6.676643558 \\
3.048780488 & -7.079730544 & -6.98140182 & -6.725433722 \\
3.003003003 & -7.098915784 & -7.0086812 & -6.759335274 \\
2.985074627 & -7.106206218 & -7.02316613 & -6.830794238 \\
\hline
\end{tabular}

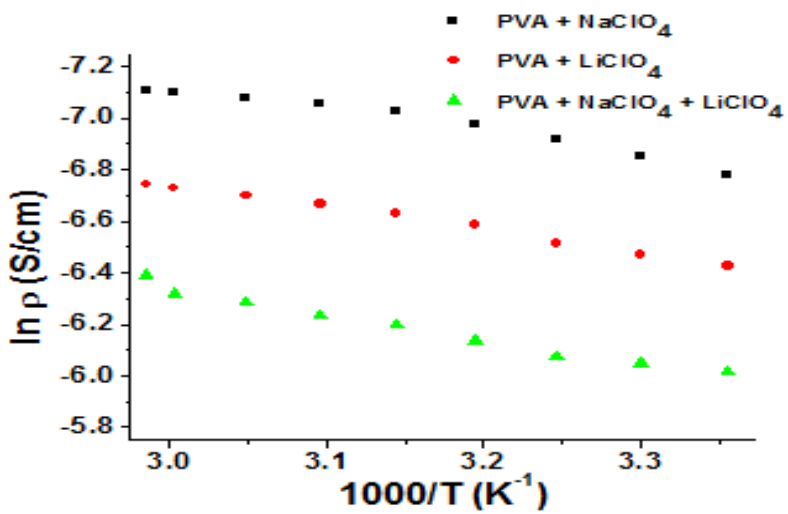

Fig. 3: Temperature Dependence Conductivity of $\mathrm{PVA} / \mathrm{NaClO}_{4}$, PVA/LiClO 4 and $\mathrm{PVA} / \mathrm{NaClO}_{4}+\mathrm{LiClO}_{4}$.

\section{Conclusions}

In the present report, we have synthesized a mixed-ion composite polymer electrolyte by addition of sodium perchlorate $\left(\mathrm{NaClO}_{4}\right)$ and lithium perchlorate $\left(\mathrm{LiClO}_{4}\right)$ to PVA solution in water. The observed conductivity of $\mathrm{PVA} /$ sodium perchlorate and PVA/lithium perchlorate composites were $1.14 \times 10^{-3} \mathrm{~S} / \mathrm{cm}$ and $1.22 \times 10^{-3} \mathrm{~S} / \mathrm{cm}$ respectively at $298 \mathrm{~K}$. The conductivity of mixedion composite polymer electrolyte having high concentrations of PVA was found to be $1.57 \times 10^{-3} \mathrm{~S} / \mathrm{cm}$ at $298 \mathrm{~K}$. On increasing the temperature, a significant decrease in the conductivity values was evident for PVA/sodium perchlorate and PVA/lithium perchlorate composites reaching upto $8.20 \times 10^{-4} \mathrm{~S} / \mathrm{cm} \& 8.91 \times 10^{-4} \mathrm{~S} / \mathrm{cm}$ respectively at $335 \mathrm{~K}$. On the other hand, negligible reduction in the conductivity value could be observed for mixed-ion composite polymer electrolyte $\mathrm{PVA}+\mathrm{NaClO}_{4}+\mathrm{LiClO}_{4}$. The temperature dependence conductivity obeyed Arrhenius behavior. The complexation and bonding between host polymer and salts to form PVA- $\mathrm{NaClO}_{4}-\mathrm{LiClO}_{4}$ complex ions was evident from FTIR spectroscopy. X-ray diffraction analysis of mixed ion composites revealed the transition from crystalline to amorphous structure by addition of the salts. These studies suggest that new mixed-ion composite polymer electrolyte can be used in electrochemical devices.

\section{Acknowledgements}

The authors are thankful to All India Council of Technical Education (AICTE) for providing research grant under Research Promotion Scheme and also to Central Instrumentation Facility, Jamia Millia Islamia, New Delhi for providing XRD \& FTIR instrumental facilities. We are grateful to the Executive Director \& Dean, Faculty of Engineering and Technology, Manav Rachna International Institute of Research and Studies, Faridabad, Haryana for his kind support.

\section{References}

[1] L. Hollaway, Handbook of Polymer Composites for Engineers" Woodhead Publishing 1994. https://doi.org/10.1533/9781845698607.

[2] P.K. Varshney and Shikha Gupta, Natural Polymer based electrolytes for electrochemical devices: a review, Ionics Volume 17 Issue 6 (2011) 479-483. https://doi.org/10.1007/s11581-011-0563-1.

[3] N. Srivastava and Tuhina Tiwari, New trends in polymer electrolytes: a review, e-Polymers, No. 146 (2009).

[4] R.C. Agrawal and G.P. Pandey, Solid polymer electrolytes: materials designing and all-solid-state battery applications: an overview, J. Phys. D: Appl. Phys. 41 (2008) 223001 (18pp).

[5] M. Kurumova, D. Lopez, R. Benavente, C. Mijangos and J.M. Perena, Effect of crosslinking on mechanical and thermal properties of poly (vinyl alcohol), Polymer Vol. 419 (2000) 9265-9272. https://doi.org/10.1016/S0032-3861(00)00287-1.

[6] A.A. Mohamad, N. S. Mohamad, M. Z. A. Yahya et al., Ionic conductivity studies of poly(vinyl alcohol) alkaline solid polymer electrolyte and its use in nickel-zinc cells, Solid State Ionics 156 (2003) 171-177. https://doi.org/10.1016/S0167-2738(02)00617-3.

[7] S. Saito, Salt Effect on Polymer Solutions, Journal of Polymer Science: Part A-1 Vol. 7 (1969) 1789-1802. https://doi.org/10.1002/pol.1969.150070719.

[8] U. Baishya and D. Sarkar, Structural and optical properties of zinc sulphide-polyvinyl alcohol (ZnS-PVA) nanocomposite thin films: effect of Zn source concentration, Bull. Mater. Sci., Vol. 34 No. 7 (2011) 1285-1288. https://doi.org/10.1007/s12034-011-0316-9.

[9] F. Ahmad and E. Sheha, Preparation and physical properties of (PVA) ${ }_{07}(\mathrm{NaBr})_{03}\left(\mathrm{H}_{3} \mathrm{PO}_{4}\right)_{x M}$ solid acid membrane for phosphoric acid - Fuel cells, Journal of Advanced Research 4 (2013) 155-161. https://doi.org/10.1016/j.jare.2012.05.001.

[10] M. Belal Abdel-Samiea, Rania Gamal and Eslam M. Sheha, Effect of Succinonitrile on Electrical, Structural and Thermal Properties of PVA-Based Polymer Electrolyte for Magnesium Battery, Journal of Energy and Power Engineering 8 (2014) 1159-1165.

[11] M. Deepa, N. Sharma, S. A. Agnihotry, R. Chandra and S. S. Sekhon, Effect of mixed salts on the properties of gel polymeric electrolytes, Solid State Ionics, Volume 148 (2002) 451-455. https://doi.org/10.1016/S0167-2738(02)00086-3.

[12] S. Rajendran, M. Sivakumar and R. Subadevi, Li-ion conduction of plasticized PVA solid polymer electrolytes complexed with various lithium salts, Solid State Ionics Volume 167 (2004) 335-339. https://doi.org/10.1016/j.ssi.2004.01.020.

[13] S. Rajendran and O. Mahendran, Experimental Investigations on Plasticized PMMA/PVA Polymer Blend Electrolytes. Ionics 7 (2001) 463-468. https://doi.org/10.1007/BF02373585.

[14] R. Gamal, Eslam Sheha, Nabil Shash, and Mervat G. El-Shaarawy, Preparation and characterization of $\mathrm{Mg}_{2}{ }^{+}$-ion conducting composite based on poly (vinyl alcohol) with various concentrations of $\mathrm{Li}_{2} \mathrm{O}$, Mater. Express, Vol. 4 No. 4 (2014) 293-300. https://doi.org/10.1166/mex.2014.1178.

[15] P. Joge, Dinesh Kumar Kanchan, Poonam Sharma and Nirali Gondaliya, Effect of nano-filler on electrical properties of PVAPEO blend polymer electrolyte, Indian Journal of Pure \& Applied Physics, Vol. 51 (2013) 350-353.

[16] J. Naik, R.F. Bhajantri, T. Sheela and Sunil G. Rathod, Role of $\mathrm{ZrO}_{2}$ on Physico-Chemical Properties of PVA/ $\mathrm{NaClO}_{4}$ Composites for Energy Storage Applications, Polymer Composites (2016) 1-10.

[17] S. Rajendran, M. Shivakumar, R. Subadevi and M. Nirmala, Characterization of PVA-PVdF based solid polymer blend electrolytes, Physica B: Condensed Matter Volume 348 Issues 1-4 (2004) 73 78. https://doi.org/10.1016/j.physb.2003.11.073.

[18] T. Sheela, R.F. Bhajantri, P.M.G. Nambissan et al., Ionic conductivity and free volume related microstructural properties of $\mathrm{LiClO}_{4} / \mathrm{PVA} / \mathrm{NaAlg}$ polymer composites: Positron annihilation spectroscopic studies, Journal of Non-Crystalline Solids, Volume 454 (2016) 19-30. https://doi.org/10.1016/j.jnoncrysol.2016.10.010.

[19] S. Gupta and Pradeep K. Varshney, Effect of plasticizer concentration on structural and electrical properties of hydroxyethyl cellulose (HEC)-based polymer electrolyte, Volume 23, Issue 6 (2017) 1613-1617.

[20] N. Kanagathara, M.K. Marchewka, M. Drozd et al., FT-IR, FTRaman spectra and DFT calculations of melaminium perchlorate monohydrate, Spectrochimica Acta Part A: Molecular and Biomolecular Spectroscopy Volume $112 \quad$ (2013) 343-350. https://doi.org/10.1016/j.saa.2013.04.001.

[21] Huang Sheng-Jian, Hoi-Kwan Lee and Won-Ho Kang, Proton Conducting Behavior of a Novel Composite Based on Phosphosili- 
cate/Poly (Vinyl Alcohol), Journal of the Korean Ceramic Society, Volume 42 Issue 2 (2005) 77-80.

[22] R.M. Hodge, G.H. Edward and G.P. Simon, Water absorption and states of water in semi crystalline poly (vinyl alcohol), Polymer Vol. 37 (1996) 1371-1376. https://doi.org/10.1016/00323861(96)81134-7.

[23] P. Balaji Bhargav, V. Madhu Mohan, A.K. Sharma and V.V.R. Narasimha Rao, Investigations on electrical properties of (PVA:NaF) polymer electrolytes for electrochemical cell applications, Current Applied Physics, Vol. 9 (2009) 165-171. https://doi.org/10.1016/j.cap.2008.01.006.

[24] R. Baskaran, S. Selvasekarapandian, N. Kuwata, J. Kawamura and T. Hattori, Structure, thermal and transport properties of PVAcLiClO4 solid polymer electrolytes, J. Phys. Chem. Solids Vol. 68 (2007) 407-412. https://doi.org/10.1016/j.jpcs.2006.12.001.

[25] Chin-Shen Lim, S. Rameshn and S.R. Majid, The effect of antimony trioxide on poly (vinyl alcohol)-lithium perchlorate based polymer electrolytes, Ceramics International 39 (2013) 745-752. https://doi.org/10.1016/j.ceramint.2012.06.087.

[26] S. Srivastava and Pradeep K. Varshney, A structural study of mixed ion PVA based composite polymer electrolyte using X-ray diffraction studies, International Journal of Applied Engineering Research Volume 12 Number 11 (2017) 2926-2928.

[27] F.M. Gray, Solid polymer electrolytes fundamentals and technological applications, VCH 1991.

[28]N. Arora and S.S. Sekhon, Conductivity studies on lithium perchlorate containing liquid and gel electrolytes, Solid State Ionics (2000) 411-415. https://doi.org/10.1142/9789812791979_0063.

[29] S.S. Sekhon, Rajiv Kumar and Boor Singh, Conductivity enhancement with polymer addition in non-aqueous polymer gel electrolytes, Solid State Ionics (2004) 911-922. 